\title{
COMPARISON OF HUMAN PLATELET LYSATE AND FETAL BOVINE SERUM IN CULTURE MEDIA FOR HUMAN DENTAL PULP STEM CELL PROLIFERATION
}

\author{
DINI ASRIANTI, ANGGRAINI MARGONO*, SILVIANA SWASTININGTYAS, ILMILDA SANDY RATNA ASRI, \\ MUNYATI USMAN, INDAH YULIANTO
}

Department of Conservative Dentistry, Faculty of Dentistry, Universitas Indonesia, Jakarta, Indonesia. Email: margonodewi@yahoo.com

Received: 26 October 2018, Revised and Accepted: 07 February 2019

\section{ABSTRACT}

Objective: Ex vivo and in vitro cell cultures require a basal medium with added supplements containing growth factors, proteins, and enzymes to support attachment, growth, and proliferation. Fetal bovine serum (FBS) is used to supplement cell culture media. However, human platelet lysate (hPL) represents an attractive alternative as it is nonxenogeneic.

Methods: Human third molars were collected from six healthy donors (19-35 years old) with no history of regular alcohol consumption or smoking. Human dental pulp stem cells (hDPSCs) at the second passage were divided into two culture media groups, $10 \% \mathrm{FBS}$ and $5 \% \mathrm{hPL}$, as well as a control group after $24 \mathrm{~h}$ of serum starvation. A flow cytometry analysis was conducted to measure CD90, CD105, CD73, CD34, CD45, and Human Leukocyte Antigen-DR isotype (HLA-DR). Cellular proliferation was evaluated on days 1, 3, and 5.

Results: The flow cytometry analysis revealed that the majority of the cells expressed positive mesenchymal stem cell surface markers, including CD73 (98.5\%), CD90 (98.3\%), and CD105 (71.0\%), and lacked CD34, CD45, and HLA-DR. There were significant differences among the 5\% hPL, 10\% FBS, and control groups on days 1,3 , and 5 .

Conclusion: For a nonxenogeneic culture, $5 \% \mathrm{hPL}$ can be used as an alternative in culture media for hDPSC proliferation.

Keywords: Human platelet lysate, Fetal bovine serum, Human dental pulp stem cells proliferation.

(C) 2019 The Authors. Published by Innovare Academic Sciences Pvt Ltd. This is an open access article under the CC BY license (http://creativecommons. org/licenses/by/4. 0/) DOI: http://dx.doi.org/10.22159/ijap.2019.v11s1.16025

\section{INTRODUCTION}

Immature teeth are at risk for developing pulpal necrosis due to trauma, caries, and anatomical variations[1]. Routine root canal treatment protocols to clean and obturate these teeth cannot be adequately performed on immature roots [2]. As an alternative technique, regenerative endodontic procedures are intended to promote tooth survival and function [1]. The American Association of Endodontists adopted the term "regenerative endodontics" in 2007 on the basis of a tissue engineering concept [3]. Nakashima described the three essential components of tissue engineering: Stem cells, bioactive growth factors, and biomimetic three-dimensional scaffolds [3-5]. These three components play an essential roles in the restoration of previously damaged structures [4].

Human dental pulp stem cells (hDPSCs) are a unique type of mesenchymal stem cells (MSCs) that are present in the cell-rich zone and core of the dental pulp. On isolation and culture in a high-serum medium, rapidly proliferating hDPSCs are capable of differentiating into mesenchymal-derived odontoblasts, osteoblasts, adipocytes, and chondrocytes, depending on the type of regulatory molecules present [6,7].

Ex vivo and in vitro cell cultures require a basal medium [8]. The compositions of cell culture media still closely resemble formulas that were developed in the pioneering work of the 1950s. Harry Eagle described basal media as a mixture of 29 essential components, including 13 amino acids, 9 vitamins, 1 D-glucose, and 6 inorganic salts [9]. In the early days of cell culture, this type of basal medium required supplements, including growth factors, proteins, and enzymes, to support attachment, growth, and proliferation $[8,9]$. In most clinical trials, including the first hDPSC transplantation, fetal bovine serum (FBS) has been used as the main nutritional supplement [8,9]. FBS is used to supplement cell culture media, because the fetal milieu is enriched in growth factors, compared with that from mature animals, and has a low concentration of antibodies. In contrast to plasma, serum contains a variety of growth factors, cytokines, and chemokines derived during blood coagulation [10].

FBS creates an obstacle for use in clinical trials as it carries a risk of the proteins initiating a xenogeneic response, protracted expansion times, exposure to zoonosis, and allergic side effects [6,11]. Recently, several groups have demonstrated that human platelet lysate (hPL) represents an attractive alternative to FBS that permits the scale-up of MSCs [6]. $\mathrm{hPL}$ is generated by subjecting common platelet units to several freezethaw cycles that damage the platelet membranes and release growth factors into the plasma [6]. Therefore, hPL can replace FBS in many cell culture systems that have previously been solely dependent on the presence of FBS [8]. Griffiths et al. stated that 5\% hPL accelerates cellular proliferation and produces smaller cell size on the proliferation of bone marrow stromal cells [12].

Recently, hPL has been commercially produced. UltraGROTM ${ }^{\circledR}$ is a commercially manufactured hPL that requires heparin to activate growth factors [13]. Existing research on this product has been focused on the proliferation of bone marrow stromal cells, so further research is required to determine its effect on the proliferation of hDPSCs, especially in the early phase cell cycles because the G0, G1, and S phases determine cellular proliferation and its proportion during the first 3 days. In these phases, growth factors play a role in proliferation [14].

\section{METHODS}

This study was approved by the Ethics Committee of the Faculty of Dentistry, Universitas Indonesia (no. 133/ethical approval/FKGUI/ XII/2017, no. Protocol: 051331017). Six human third molars were 
collected at Oral Surgery Department, Faculty of Dentistry, Universitas Indonesia, from 19 to 35-year-old healthy donors with no history of alcohol or smoking. Teeth were transferred to the cell culture laboratory where stem cells from the pulp tissues were isolated. Briefly, the tooth was cut around the cementoenamel junction, and then the pulp tissue was gently removed from the chambers, sliced into $0.5-1.0 \mathrm{~mm}$ sections, and diluted in an enzyme solution that consisted of $3.0 \mathrm{mg} / \mathrm{mL}$ collagenase type I and $4.0 \mathrm{mg} / \mathrm{mL}$ dispase (Sigma-Aldrich, St. Louis, MO, USA) for $30-60 \mathrm{~min}$ at $37^{\circ} \mathrm{C}$. The mixture was cultured in $3 \mathrm{~mL}$ of Dulbecco's Modified Eagle's Medium supplemented with 10\% FBS (HyClone), $100 \mathrm{U} / \mathrm{mL}$ penicillin G (Roche, Basel, Switzerland), and 100 $\mathrm{mg} / \mathrm{mL}$ streptomycin (Roche) and incubated in an atmosphere of $5 \%$ $\mathrm{CO}_{2}$ at $37^{\circ} \mathrm{C}$.

Table 1: The mean analysis of hDPSCs proliferation in three different growth media groups on day 1

\begin{tabular}{lllll}
\hline Groups & $\mathbf{n}$ & Mean & SD & $\mathbf{p}$ \\
\hline Control & 6 & 7.88 & 0.29 & $0.001^{*}$ \\
$10 \%$ FBS & 6 & 229.36 & 6.09 & \\
$5 \%$ hPL & 6 & 78.15 & 2.87 & \\
\hline
\end{tabular}

${ }^{*}$ ANOVA test, $\mathrm{p}<0.05$. FBS: Fetal bovine serum, hpL: Human platelet lysate, hDPSCs: Human dental pulp stem cells

Table 2: The mean analysis of hDPSCs proliferation in three different growth media groups on day 3

\begin{tabular}{lllll}
\hline Groups & $\mathbf{n}$ & Median & Max - Min & $\mathbf{p}$ \\
\hline Control & 6 & 8.55 & $8.30-11.20$ & $0.001^{*}$ \\
$10 \%$ FBS & 6 & 2199.04 & $531.40-3144.58$ & \\
$5 \% \mathrm{hPL}$ & 6 & 11.16 & $101.85-140.20$ & \\
\hline
\end{tabular}

*Kruskal-Wallis test, $\mathrm{p}<0.05$. FBS: Fetal bovine serum, hpL: Human platelet lysate, hDPSCs: Human dental pulp stem cells

Table 3: The mean analysis of hDPSCs proliferation in three different growth media groups on day 5

\begin{tabular}{lllll}
\hline Groups & $\mathbf{n}$ & Median & Max-Min & $\mathbf{p}$ \\
\hline Control & 6 & 10 & $9.10-14.70$ & $0.001^{*}$ \\
$10 \% \mathrm{FBS}$ & 6 & 2381.70 & $448.51-367.63$ & \\
$5 \% \mathrm{hPL}$ & 6 & 18.79 & $14.63-104.43$ & \\
\hline
\end{tabular}

*Kruskal-Wallis test, $\mathrm{p}<0.05$. FBS: Fetal bovine serum, hpL: Human platelet lysate, hDPSCs: Human dental pulp stem cells

Table 4: The difference of hDPSCs proliferation between three different growth media groups on 3 times observations

\begin{tabular}{llll}
\hline Groups & $\begin{array}{l}\text { Day 1 } \\
\text { p value }\end{array}$ & $\begin{array}{l}\text { Day 3 } \\
\text { p value }\end{array}$ & $\begin{array}{l}\text { Day 5 } \\
\text { p value }\end{array}$ \\
\hline Control versus 10\% FBS & $0.001^{*}$ & $0.004^{*}$ & $0.004^{*}$ \\
Control versus 5\% hPL & $0.001^{*}$ & $0.004^{*}$ & $0.010^{*}$ \\
$10 \%$ FBS versus 5\% hPL & $0.001^{*}$ & $0.004^{*}$ & $0.004^{*}$ \\
\hline
\end{tabular}

*Tamhane test, $\mathrm{p}<0.05$; Mann-Whitney U-test, $\mathrm{p}<0.05$. FBS: Fetal bovine serum, hpL: human platelet lysate, hDPSCs: Human dental pulp stem cells
When the cells reached $80 \%$ confluency, single cell clones were isolated by limiting the dilution. The cells used in this study were in the second or third passage. hDPSCs at the second passage were divided into two culture media groups, $10 \% \mathrm{FBS}$ and $5 \% \mathrm{hPL}$, as well as a control group after $24 \mathrm{~h}$ of serum starvation, with each group containing six biological replicates. Serum starvation procedures were performed according to a previously published method [15]. The hPL culture media used in this study consisted of $5 \%$ hPL from a commercial product culture medium (Helios UltraGRO). The preparation of this product was carried out as per the manufacturer's instructions.

A flow cytometry analysis was conducted using FACSVerse (BD Biosciences), and data were analyzed using FlowJo software. The tested markers included CD90, CD105, and CD73 as a positive cocktail of MSCs and CD34, CD45, and Human Leukocyte Antigen-DR isotype (HLADR) as a negative cocktail. During days 1,3 , and 5, the proliferation of hDPSCs was evaluated using a 3-(4,5-dimethylthiazol-2-yl)-2,5diphenyltetrazolium bromide assay according to the manufacturer's instructions. Data analysis for the potential ability of each group was analyzed using one-way analysis of variance (ANOVA) or MannWhitney U-test, and differences between days 1,3 , and 5 were analyzed using the one-way ANOVA, Kruskal-Wallis or Friedman test.

\section{RESULTS}

Flow cytometry revealed that the majority of cells expressed hDPSC positive surface markers, including CD73 (98.5\%), CD90 (98.3\%), and CD105 (71.0\%), and were negative for CD34, CD45, and HLA-DR Fig. 1. The result of statistical analysis hDPSCs proliferation consists of three different growth media groups; the control group was cells after $24 \mathrm{~h}$ of serum starvation with 1\% FBS, 10\% FBS group, and 5\% hPL group.

The statistical results of the mean value of proliferation in hDPSCs on the day 1 showed that $5 \% \mathrm{hPL}$ proved to have the ability to initiate proliferation in hDPSCs as well as 10\% FBS Table 1. The highest proliferation rate of hDPSCs in this study was with 10\% FBS (2381.70) on day 5 and $5 \%$ hPL (111.16) on day 3 Table 2 and 3. The proliferation of hDPSCs between the three groups was significantly different on days 1,3 , and 5 Table 4 and 5.

\section{DISCUSSION}

This study highlights hPL as a replacement for FBS in culture media for the proliferation of hDPSCs [16]. hDPSCs were first isolated from teeth in 2000 by Gronthos et al. and are considered a primary source of MSCs. MSCs are multipotent progenitors that can differentiate into multiple cell lineages, such as osteoblasts, adipocytes, and chondrocytes. MSCs are currently expanded in vitro, either under experimental or under clinical-grade conditions in the presence of $10-20 \%$ FBS, which is considered crucial for the in vitro expansion of MSCs $[7,9]$

The possibility of using animal-free culture media has been reported in several recent studies by substituting FBS with human-derived supplements such as hPL or human serum $[7,16]$. Media preparations have already been demonstrated to be a powerful source of growth factors, useful in the treatment of a variety of soft and hard tissue conditions [7].

We tested two different supplement culture media for hDPSCs, that is, $10 \% \mathrm{FBS}$ and $5 \% \mathrm{hPL}$, at 3 evaluation times (days 1, 3, and 5). Our data

Table 5: The analysis of hDPSCs proliferation in three different growth media groups on 3 times observations

\begin{tabular}{lllll}
\hline \multirow{2}{*}{ Groups } & \multicolumn{2}{l}{ Proliferation of hDPSCs at $\mathbf{3}$ times observations (\%) } & p-value \\
\cline { 2 - 4 } & 1 Day mean \pm SD & 3 Days median (Min-Max) & 5 Days median (Min-Max) & \\
\hline Control & $7.88 \pm 0.29$ & $8.55(8.30-11.20)$ & $10(9.10-14.70)$ & $0.002^{*}$ \\
$10 \%$ FBS & $229.36 \pm 6.09$ & $2199.04(531.40-3144.58)$ & $2381.70(448.51-367.63)$ & $0.009^{*}$ \\
$5 \%$ hPL & $78.15 \pm 2.87$ & $111.16(101.85-140.20)$ & $18.79(14.63-104.43)$ & 0.135 \\
\hline
\end{tabular}

*Friedman test, $\mathrm{p}<0.05$. FBS: Fetal bovine serum, hpL: human platelet lysate, hDPSCs: Human dental pulp stem cells 


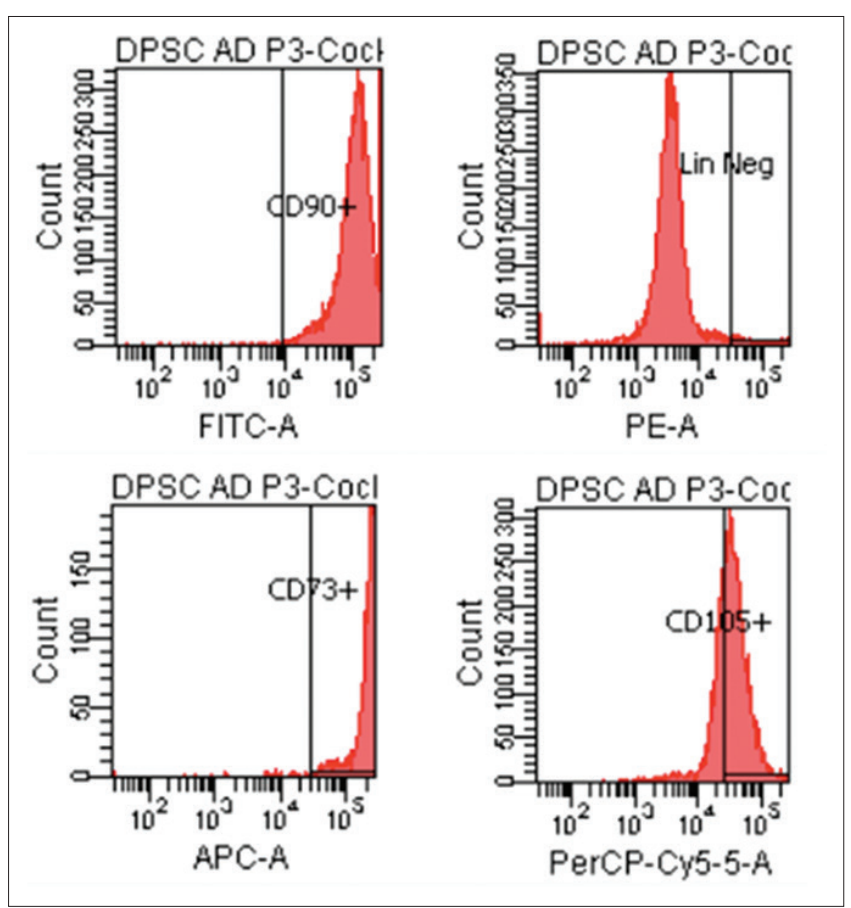

Fig. 1: Flow cytometry of human dental pulp stem cell

demonstrated that $10 \%$ FBS is superior to $5 \% \mathrm{hPL}$ in terms of potential proliferative ability. This result is in accordance with a previous study by Ma et al. that compared FBS with $1 \%$ and $2 \% \mathrm{hPL}$, where hPL showed a higher proliferation rate during the $1^{\text {st }}$ days of culture, whereas $5 \% \mathrm{hPL}$ never surpassed FBS [17]. On the contrary, Masuki et al. concluded that $5 \% \mathrm{hPL}$ had a significantly higher proliferation rate when compared with $10 \%$ FBS [18]. The variability in hPL manufacturing influences the content of the primary growth factors that result in cell proliferation $[17,18]$. hPL contains a pool of endogenous growth factors, such as TGF- $\beta$, PDGF, FGF, and IGF. These growth factors have been shown to enhance MSC expansion under in vitro conditions, but it should be noted that the level of growth factors varies considerably between species and donors [6].

We observed a decrease in the proliferation of hDPSCs with 5\% hPL after days 3 . This result met our expectations, as explained in a study by Saeed et al., who showed that the proliferation of hDPSCs at the $1^{\text {st }}$ day and had an inhibitory growth pattern on day 3 and after [11]. Furthermore, the G0 phase of the cell cycle requires growth factors to allow the cell to enter the cycle while preparing for DNA synthesis. The G1 phase determines the development of cell shape and size. The G0, G1, and S phases determine cellular proliferation and its proportion during the first 3 days. In these phases, growth factors play a role in proliferation [14].

In this study, we aimed to analyze the proliferation of hDPSCs in $10 \%$ FBS compared with $5 \% \mathrm{hPL}$ as an alternative culture medium. The mean proliferation on day 1 showed that $5 \%$ hPL could initiate the proliferation of hDPSCs as well as $10 \%$ FBS. The overgrowth cells on $10 \%$ FBS may indicate that the proliferation was not in the proper cell cycle, but this result still needs further confirmation. Moreover, hPL can be considered as an alternative for cell-based therapies, such as tissue engineering and regenerative approaches.

\section{CONCLUSION}

It can be concluded that $5 \% \mathrm{hPL}$ has the capacity for hDPSC proliferation as well as $10 \%$ FBS on day 1 due to the high concentration of natural growth factors contained in hPL. Therefore, hPL can be considered an alternative culture media supplement for hDPSCs but in limited observation time. Further research using other type of platelet culture media still need to be conducted.

\section{ACKNOWLEDGMENT}

We thank our colleagues, Yanni Dirgantara S.Si and Emilia Rahmadaniah Utami, S.Si from ProSTEM Laboratory, and collaborators for their excellent experimental assistance and discussions.

\section{CONFLICTS OF INTEREST}

There are no conflicts of interest to declare.

\section{REFERENCES}

1. Diogenes A, Ruparel NB, Shiloah Y, Hargreaves KM. Regenerative endodontics a way forward. J Am Dent Assoc 2016;147:372-80.

2. Torabinejad M, Nosrat A, Verma P, Udochukwu O. Regenerative endodontic treatment or mineral trioxide aggregate apical plug in teeth with necrotic pulps and open apices: A Systematic review and metaanalysis. J Endod 2017;43:1806-20.

3. Kim SG, Malek M, Sigurdsson A, Lin LM, Kahler B. Regenerative endodontics: A comprehensive review. Int Endod J 2018;51:1367-88.

4. Sreedev CP, Karthick K, Mathew S, Raju I. Regenerative endodontics: An overview. J Indian Acad Dent Spec Res 2017;4:18-22.

5. Mookhtiar H, Hegde V, Shanmugsundaram S. A new innovation in dentistry: Regenerative endodonics. Int J Rec Sci Res 2018;9:24881-7.

6. Chen B, Sun HH, Wang HG, Kong H, Chen FM, Yu Q, et al. The effects of human platelet lysate on dental pulp stem cells derived from impacted human third molars. Biomaterials 2012;33:5023-35.

7. Bernardo ME, Avanzini MA, Perotti C, Cometa AM, Moretta A, Lenta E, et al. Optimization of Io expansion of human multipotent mesenchymal stromal cells for cell-therapy approaches: Further insights in the search for a fetal calf serum substitute. J Cell Physiol 2007;211:121-30.

8. Govindasamy V, Ronald VS, Abdullah AN, Ganesan Nathan KR, Aziz ZA, Abdullah M, et al. Human platelet lysate permits scale-up of dental pulp stromal cells for clinical applications. Cytotherapy 2011;13:1221-33.

9. Hemeda H, Giebel B, Wagner W. Evaluation of human platelet lysate versus fetal bovine serum for culture of mesenchymal stromal cells. Int Soc Cell Ther 2014;16:170-80.

10. Bieback K. Platelet lysate as replacement for fetal bovine serum in mesenchymal stromal cell cultures. Transfus Med Hemother 2013;40:326-35

11. Saeed MA, El-Rahman MA, Helal ME, Zaher AR, Grawish ME. Efficacy of human platelet rich fibrin exudate vs fetal bovine serum on proliferation and differentiation of dental pulp stem cells. Int J Stem Cells 2017;10:38-47.

12. Griffiths S, Baraniak PR, Copland IANB, Nerem RM, Mcdevitt TC. Human platelet lysate stimulates high-passage and senescent human multipotent mesenchymal stromal cell growth and rejuvenation in vitro. J Cytotherapy 2013;15:1469-83.

13. Biomedical Corporation. UltraGROTM Product Description. Alpharetta: Biomedical Corporation; 2015. p. 1-2.

14. Marsa RD, Asrianti D, Margono A. The efficacy of platelet-rich fibrin lysate (PRF-L) for fibroblast cell proliferation. J Int Dent Med Res 2017;10:809-13.

15. Ben Azouna N, Jenhani F, Regaya Z, Berraeis L, Ben Othman T, Ducrocq E, et al. Phenotypical and functional characteristics of mesenchymal stem cells from bone marrow: Comparison of culture using different media supplemented with human platelet lysate or fetal bovine serum. Stem Cell Res Ther 2012;3:6.

16. Marrazzo P, Paduano F, Palmieri F, Marrelli M, Tatullo M. Highly efficient in vitro reparative behaviour of dental pulp stem cells cultured with standardised platelet lysate supplementation. Stem Cells Int 2016;2016:7230987.

17. Ma Y, Reilly S, Fischer S, Henshaw M, Pierce J, Poudel A, et al. Human platelet lysate produced at industrial scale for use as fetal bovine serum replacement in cell manufacturing protocols. Cytotherapy 2015;17:S41.

18. Masuki H, Okudera T, Watanebe T, Suzuki M, Nishiyama K, Okudera H, et al. Growth factor and pro-inflammatory cytokine contents in plateletrich plasma (PRP), plasma rich in growth factors (PRGF), advanced platelet-rich fibrin (A-PRF), and concentrated growth factors (CGF). Int J Implant Dent 2016;2:19. 